\title{
Feasibility Study of Evaporative Water Cooled (EWC) Grinding Method for Chilli (Capsicum annum L.)
}

\author{
D.M.S.P. Bandara ${ }^{*}$, K.S.P. Amarathunga ${ }^{1}$, B.M.K.S. Thilakaratne ${ }^{1}$, T.M.R. Dissanayake ${ }^{1}$, \\ D.A.N. Dharmasena ${ }^{2}$, A.J. Fernando ${ }^{2}$
}
Postgraduate Institute of Agriculture
University of Peradeniya,
Peradeniya

\begin{abstract}
The application of low temperature grinding shows promising pathway to produce higher quality ground product in terms of flavour and volatile oil retention of spices. The possibility of using evaporative water cooling for grinding chilli was studied to ascertain the quality parameters. Atomized water was sprayed on to the chilli pods being fed in to the mill. The temperature, moisture content and colour values of the ground product were measured and the values were compared with conventional grinding. The temperature of the conventionally ground and evaporative water cooled ground chilli were $58 \pm 2.65{ }^{\circ} \mathrm{C}$ and $36 \pm 1.5{ }^{\circ} \mathrm{C}$ respectively and the corresponding amounts of heat removed by water vapour were $29.33 \mathrm{~kJ}$ and $186.50 \mathrm{~kJ}$. The moisture content of conventionally ground chilli and evaporative water cooled ground chilli with water spraying were $9.06 \pm 0.41$ and $9.65 \pm$ 0.23 percent wet basis and the corresponding colour values were $49.19 \pm 0.99\left(L^{*}\right), 17.35 \pm$ $1.62\left(a^{*}\right), 23.38 \pm 1.29\left(b^{*}\right)$ and $47.52 \pm 1.74\left(L^{*}\right), 18.38 \pm 0.14\left(a^{*}\right)$ and $26.93 \pm 0.68$ $\left(b^{*}\right)$. This study revealed that the water can be effectively used as a coolant for reducing temperature rise during grinding in order to preserve the quality of chilli.
\end{abstract}

Keyword: Chilli, evaporation cooling, grinding, spice

\section{INTRODUCTION}

Chilli (Capsicum annuum L.) is a important spice in human food and a fruit vegetable widely cultivated in the world (Dias et al., 2013; Wahyuni et al., 2013). Grinding is one of the important unit operations in the post-harvest processing of spices. The reasons for reducing size of a material are to create appropriate particle size for subsequent processing or end use, create a free-flowing material, improve material blending and prevent segregation by making products in different size ranges and increase the material's surface area to improve a material's reactiveness and drying efficiency (Wennerstrum et al., 2002).

Grinding is the most power consuming operation because only $1 \%$ of the energy imparted into the material is utilized in loosening the bond between particles, whereas almost $99 \%$ of input energy is dissipated as heat, raising the temperature of the ground product. According to Singh and Goswami (1997) the temperature rises to the range of $42-93{ }^{\circ} \mathrm{C}$ in spice

\footnotetext{
Institute of Post harvest Technology, Jayanthi Mawatha, Anuradhapura, Sri Lanka

Department of Agriculture Engineering, Faculty of Agriculture, University of Peradeniya, Sri Lanka

2 Department of Agricultural Engineering and Soil Science, Faculty of Agriculture, Rajarata University of Sri

Lanka, Puliyankulama, Anuradhapura, Sri Lanka

Corresponding author: srimapriyagika@yahoo.com
} 
grinding. It causes a loss of volatile oil and flavouring constituents for materials with high oil content, oil comes out during grinding, which makes the ground product gummy, sticky and results in chocking of sieves through which the product passes.

During grinding, the temperature of a product rises to a level in the range of $42-95{ }^{\circ} \mathrm{C}$ (Pruthi and Misra, 1963), which varies with the oil and moisture content of the spices. The spices lose a significant fraction of their volatile oil or flavouring components due to temperature rise. The losses of volatile oil for different spices have been reported to be about $37 \%$ for nutmeg, $14 \%$ for mace, $17 \%$ for cinnamon and $17 \%$ for oregano (Andres, 1976). The loss of volatile oil during grinding of caraway seed has been reported to be $32 \%$ with an increase in grinding temperature from -17 to $45^{\circ} \mathrm{C}$ (Wolf and Pahl, 1990).

Thermal damage is one of the main limitations of the conventional milling process. Malkin and Guo (2007) suggested that a better product could be obtained by reducing the temperature of the two rubbing surfaces. The temperature rise of the product can be minimized to some extent by circulating cold air or water around the grinder. But this technique is not sufficient enough to significantly reduce the temperature rise of the product. The extremely low temperature in the grinder solidifies the oil, therefore that the spices become brittle; they crumble easily permitting grinding to a finer and more consistent size. The high quality ground product would have domestic as well as international market (Meghwal and Goswami, 2010).

Pre-cooling of the raw spice and the continuous low temperature maintained within the mill reduces loss of volatile oil, thereby, retaining most of the flavour strength per unit mass of spice (Mathew and Sreenarayanan, 2007). Evaporation describes the process of energetic particles leaving a system with a finite binding energy. This process result in cooling since the evaporating particles carry away more than their share of thermal energy resulting in decrease of the temperature of the system (Ketterle and Van Druten, 1996).

The objective of this research was to study the feasibility of using evaporative water cooling (EWC) for grinding chilli.

\section{METHODOLOGY}

A homogeneous bulk sample of sun dried chilli (variety MI-2, average length $10.54 \mathrm{~cm}$, width $1.31 \mathrm{~cm}$ and thickness $0.34 \mathrm{~cm}$ ) with moisture content of $11.25 \pm 0.5 \%$ wet basis $(\mathrm{wb})$ was used for the experiment. The temperature, moisture content and colour of the evaporative water cooled (EWC) and conventionally ground chilli was measured and compared. The experiments were conducted at the Institute of Postharvest Technology, Anuradhapura.

Randomly obtained $500 \mathrm{~g}$ chilli sample from the stock was used for the grinding process with evaporative water cooling. A disk mill (model UD-23) obtained from Udaya Industries, Weligalle and installed at Institute of Postharvest Technology, Anuradhapura was used for milling chilli. The mill consisted of rotating disk having diameter of $0.23 \mathrm{~m}$ and $4 \mathrm{~kW}$ single phase motor. A 500 micron sieve was selected to obtain the required particle size (Sri Lankan Standard Institute, 1988). A spray gun (model of DCS-142, iwata, USA) and a compressor $(0.2 \mathrm{~kW}$ and $1440 \mathrm{rpm})$ was used to spray water at ambient temperature $\left(28^{\circ} \mathrm{C}\right)$ as the coolant. The water was sprayed at a rate of $1.1 \mathrm{ml} / \mathrm{sec}$ on the chilli feeding to the mill 
at the rate of $30 \mathrm{~kg} / \mathrm{h}$ and water amount of spray bottle was maintained to $70 \mathrm{ml}$ per each run. The schematic diagram of the experimental setup of grinding chilli with evaporative cooling is shown in Fig. 1. Another sample with $500 \mathrm{~g}$ of chilli was ground conventionally using the same disk mill and sieved to compare it with ground chilli sample obtained with evaporative water cooling. The treatments were replicated three times.

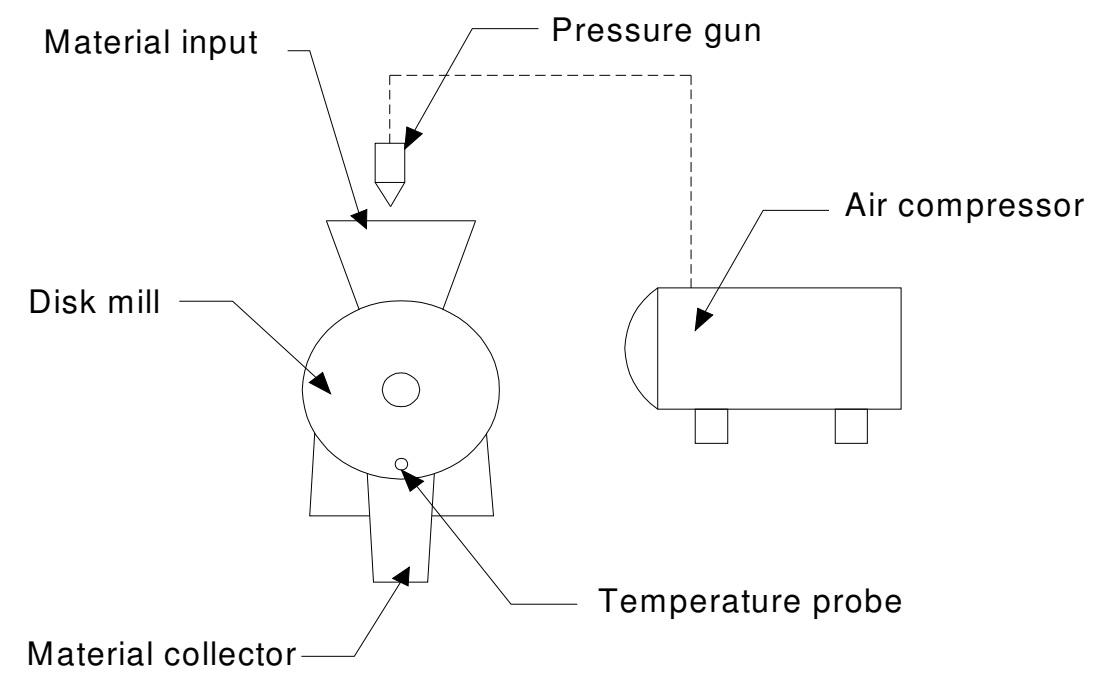

\section{Fig.1. Schematic diagram of the experimental setup of grinding chilli with evaporative water cooling.}

The temperature of the ground chilli with evaporative cooling and conventionally ground chilli was measured at the outlet of the mill using a digital thermometer (TECPEL, Model: 318 ) of accuracy $\pm 0.1{ }^{\circ} \mathrm{C}$. Colour $\left(\mathrm{L}^{*} \mathrm{a} * \mathrm{~b}^{*}\right)$ measurements were performed in five replicates using a Chroma meter (Konica Minolta, Model CR-400). According to the AOAC method, Dean and Stark apparatus was used to measure the moisture content of the ground chilli. Extracted moisture volume was measured using measuring cylinders. Then moisture content was calculated by the Eq. 1 .

$$
M c=\frac{W v \times D w}{S w} \times 100
$$

Where,

$M c$ - Moisture content $\%$ w.b., $W v$ - Water volume (ml), $D w$ - Density of water $(\mathrm{g} / \mathrm{ml})$ and $\mathrm{Sw}$-Sample weight (g)

The results were reported as the mean value \pm standard deviation. The data were subjected to analysis of variance using SAS by complete randomized design. Duncan's multiple range test was applied to determine significant differences at the $5 \%$ level of significance $(p<0.05)$. 


\section{RESULTS AND DISCUSSION}

The initial colour of chilli pods obtained for study was $33.33\left(\mathrm{~L}^{*}\right), 21.26\left(\mathrm{a}^{*}\right)$ and $14.58\left(\mathrm{~b}^{*}\right)$. The ground samples with evaporative water cooling were compared with conventionally ground samples in terms of temperature rise during milling, final moisture content and colour.

Table 1 shows the properties of ground chilli by conventional and EWC grinding. The temperature of the ground chilli by conventionally and evaporative water cooling with spraying water were $58 \pm 2.65$ and $36 \pm 1.5{ }^{\circ} \mathrm{C}$ respectively. The statistical analysis demonstrated a significant difference in temperatures.

The moisture content of ground chilli samples conventionally and with EWC were 9.06 \pm 0.41 and $9.65 \pm 0.23 \%$ (wb) (Table 1). The obtained moisture content values in both grinding method complied with the value of the Sri Lanka Standard Institution (1988). According to the statistical analysis there was no significant difference $(p<0.05)$ of moisture content in ground chilli samples by each method.

The colour values of ground chilli samples in conventionally and EWC were 49.19 \pm $0.99\left(\mathrm{~L}^{*}\right), 17.35 \pm 1.62\left(\mathrm{a}^{*}\right), 23.38 \pm 1.00\left(\mathrm{~b}^{*}\right)$ and $47.52 \pm 1.74\left(\mathrm{~L}^{*}\right), 18.38 \pm 0.14\left(\mathrm{a}^{*}\right)$, $26.93 \pm 0.68\left(b^{*}\right)$, respectively (Table 1). The lightness value was reduced in EWC ground chilli with water spraying. Redness and yellowness values were higher in EWC grinding than the conventional grinding. According to Minquez-Mosquera et al. (1992), colour of ground chilli is the principal criterion for assessing its quality and value. This colour result shows higher darkness in EWC grinding than conventional grinding.

Table 1. Properties of ground chilli by conventional and EWC grinding

\begin{tabular}{|c|c|c|c|}
\hline Parameter & & Conventional grinding & EWC grinding \\
\hline Temperature ( $\mathrm{C}$ ) & & $58^{\mathrm{a}} \pm 2.65$ & $36^{\mathrm{b}} \pm 1.5$ \\
\hline Moisture content $(\%, w b)$ & & $9.06^{\mathrm{a}} \pm 0.41$ & $9.65^{\mathrm{a}} \pm 0.23$ \\
\hline \multirow{3}{*}{ Colour } & $\mathrm{L}^{*}$ & $49.19 *^{\mathrm{a}} \pm 0.99$ & $47.52 *^{\mathrm{a}} \pm 1.74$ \\
\hline & $a^{*}$ & $17.35^{*^{\mathrm{a}}} \pm 1.62$ & $18.38 *^{* a} \pm 0.14$ \\
\hline & $b^{*}$ & $23.38 *^{\mathrm{b}} \pm 1.00$ & $26.93 *^{*^{\mathrm{a}}} \pm 0.68$ \\
\hline
\end{tabular}

* Different superscript letters differ significantly according to Duncan's multiple range test $(p<0.05)$.

Heat generated in size reduction was steered to increase the temperature of chilli product in conventional grinding while heat generated was reduced in EWC grinding due to the sprayed water vapour as sensible and latent heat during grinding. In this study, the heat load absorbed by water was considered and sensible heat of water vapour was assumed as negligible in comparison to the latent heat of water. To calculate the latent heat of water vaporization, the energy balance as shown in Eq. 2 was used (Verma, 2002).

$Q=m \lambda \quad \quad \ldots .$. Eq. 2

Where

$\mathrm{m}$ - mass of water and $\lambda$ - latent heat of water $\left(2365 \mathrm{~kJ} / \mathrm{kg}\right.$ at $\left.58{ }^{0} \mathrm{C}\right)$. 
The moisture removal was calculated by using the values of initial moisture content of chilli pods and final moisture content of ground chilli. The amount of moisture removed in conventional grinding was $12.04 \mathrm{~g}$. Therefore, the latent heat absorbed by moisture in chilli at conventional grinding was $29.33 \mathrm{~kJ}$. The amount of water sprayed in EWC grinding was $70 \mathrm{~g}$. The amount of moisture removed in EWC grinding was $78.86 \mathrm{~g}$. The calculated latent heat at EWC grinding was $186.50 \mathrm{~kJ}$. In both grinding methods, the sensible heat absorbed by chilli pods during grinding was considered as negligible when compared to the latent heat capacity of vaporized water.

\section{CONCLUSION}

The results indicated that $186.50 \mathrm{~kJ}$ of heat was removed from the ground product treated by evaporative water cooling than conventionally ground product due to the addition of water in EWC grinding. As a result, EWC grinding reduces the temperature of ground sample from $58 \pm 2.65$ to $36 \pm 1.5{ }^{\circ} \mathrm{C}$. The ground chilli obtained from EWC achieved comparable moisture content and colour values with conventionally ground chilli. Therefore it could be concluded that the evaporative water cooling for grinding chilli could be effectively used as a low temperature size reduction method. Further studies need to be carried out to investigate the amount of water to be sprayed and the method of water application within a restricted environment.

\section{REFERENCES}

Andres, C. (1976). Grinding spices at cryogenic temperatures retains volatiles and oils. Food Processing, 37(9), 52 - 53.

Dias, G.B., Gomes, V.M., Moraes, T.M., Zottich, U.P., Rabelo, G.R., Carvalho, A.O.,Moulin, M., Gonçalves, L.S., Rodrigues, R., Da Cunha, M. (2013). Characterization of Capsicum species using anatomical and molecular data, Genetics and Molecular Research 12(4), $6488-6501$.

Ketterle, W. and Van Druten, N.J. (1996). Evaporative cooling of trapped attoms. Advances in atomic, molecular and optical physics, vol. 37.

Malkin, S. and Guo, C. (2007).Thermal Analysis of Grinding. Annals of the CIRP. Connecticut, USA. Science Direct, 56 (2), 760 - 782.

Mathew, S.M and Sreenarayanan, V.V. (2007) Study on grinding of black pepper and effect of low feed temperature on product quality, Journal of Spices and Aromatic Crops, 16 (2), 82 $-87$.

Megwal, M. and Goswami T.K. (2010) Cryogenic grinding of Spices is novel approach whereas ambient grinding needs improvement. Journal of Food science and Technology, 4, 24 - 37.

Minquez- Mosquera, M.I., Jaren- Galan, M. and Garrido- Fernandez, J. (1992). Colour quality in paprika. Journal of Agricultural Food Chemistry, 40: 2384. 
Pruthi, J.S., and Misra, B.D. (1963). Spice Bull., 3(3-5), 8.

Singh, K.K. and Goswami, T.K. (1997). Studies on cryogenic grinding of spices. IIT Kharagpur (India).

Sri Lanka Standard Institution (1988). Speciation for ground chillies (First Revision), $(117: 1988)$

Verma, R.C and Jain, S.K. (2002). Fundamental of Food Engineering. Himansu Publications, Udaipur, New Delhi.

Wahyuni, Y., Ballester, A.R., Sudarmonowati, E., Bino, R.J. and Bovy, A.G. (2013). Chilli (Capsicum annuumL.) in southern Benin:production constraints, varietal diversity, preference criteria and participatory evaluation, International Research Journal of Agricultural Science and Soil Science, 3(4), 107 - 120.

Wennerstrum, S., Tomaka, T. J. and Cain, J. (2002). Size reduction solutions for hard-to reduce materials. Powder and Bulk Engineering. 1 - 5.

Wolf, T., and Pahl, M. H. (1990). Cold grinding of caraway seeds inimpact mill.

International Journal of Technology and Food ProcessEngineering, 41(10), 596 - 604. 